11 UNITED NATIONS

UNIVERSITY

\title{
UNU-MERIT
}

Working Paper Series

\#2006-44

\section{The Role of Noncognitive Skills in Explaining Cognitive Test Scores}

Lex Borghans, Huub Meijers \& Bas ter Weel 



\title{
The Role of Noncognitive Skills in Explaining Cognitive Test Scores*
}

\author{
Lex Borghans \\ Department of Economics and ROA, Maastricht University \\ l.borghans@roa.unimaas.nl \\ Huub Meijers \\ Department of Economics and MERIT, Maastricht University \\ huub.meijers@merit.unimaas.nl \\ Bas ter Weel \\ Department of Economics and MERIT, Maastricht University \\ b.terweel@merit.unimaas.nl
}

\begin{abstract}
This paper examines whether noncognitive skills - measured both by personality traits and economic preference parameters - influence cognitive tests performance. The basic idea is that noncognitive skills might affect the effort people put into a test to obtain good results. We experimentally varied the rewards for questions in a cognitive test to measure to what extent people are sensitive to financial incentives. To distinguish increased mental effort from extra time investments we also varied the questions' time constraints. Subjects with favorable personality traits such as high performance-motivation and an internal locus of control perform relatively well in the absence of rewards; consistent with a model in which trying as hard as you can is the best strategy. In contrast, favorable economic preference parameters (low discount rate, low risk aversion) are associated with increases in time investments when incentives are introduced, consistent with a rational economic model in which people only invest when there are monetary returns. The main conclusion is that individual behavior at cognitive tests depends on noncognitive skills.
\end{abstract}

Keywords: cognitive test scores; noncognitive skills JEL Codes: J20; J24

\section{UNU-MERIT Working Papers ISSN 1871-9872}

\section{Maastricht Economic and social Research and training centre on Innovation and Technology, UNU-MERIT}

UNU-MERIT Working Papers intend to disseminate preliminary results of the research carried out at the institute to stimulate discussion on the issues raised.

\footnotetext{
* We would like to thank Flavio Cunha, Bart Golsteyn, James Heckman, Joan Muysken and Inge Sieben for useful comments and conversations, participants at the 2006 WEAI in San Diego for feedback on an earlier version of this paper, and Anton de Vries for advice about the use of cognitive tests. This research has been supported by the Maastricht Graduate School of Governance.
} 



\title{
The Role of Noncognitive Skills in Explaining Cognitive Test Scores*
}

\author{
Lex Borghans \\ Department of Economics and ROA, Maastricht University \\ 1.borghans@roa.unimaas.nl \\ Huub Meijers \\ Department of Economics and MERIT, Maastricht University \\ huub.meijers@merit.unimaas.nl \\ Bas ter Weel \\ Department of Economics and MERIT, Maastricht University \\ b.terweel@merit.unimaas.nl
}

\footnotetext{
" We would like to thank Flavio Cunha, Bart Golsteyn, James Heckman, Joan Muysken and Inge Sieben for useful comments and conversations, participants at the 2006 WEAI in San Diego for feedback on an earlier version of this paper, and Anton de Vries for advice about the use of cognitive tests. This research has been supported by the Maastricht Graduate School of Governance.
} 


\section{Introduction}

This paper reports findings of an experiment to examine whether measured cognitive test scores are influenced by noncognitive skills. The basic idea of our analysis is that the performance on a cognitive test not only depends on the actual cognitive abilities a person possesses, but also depends on the willingness to put mental effort in answering difficult questions in the absence of extrinsic rewards. A relationship between noncognitive skills and cognitive test scores can exist for two reasons. First, people who are motivated to perform well, and who have a positive attitude towards work, might be more inclined to do their best at tests, irrespective of the rewards offered. If so, high IQ-scores might partly reflect favorable noncognitive skills and correlations between cognitive skills and outcomes are upward biased. Second, people with favorable behavioral or labor-market outcomes might have an attitude to put effort in a task only when there are sufficient rewards. This could serve as an explanation for a successful career despite lower cognitive test scores at school.

To investigate the relationship between noncognitive skills and cognitive test scores, we performed an experiment in which we first measured psychological traits and economic preference parameters of 128 students. Next, these students carried out a cognitive test. Initially there were no rewards for right answers, but later on we introduced payments for right answers. To disentangle the effect of increased mental effort from increased time investments we also varied the time available for each question. To investigate whether our results are affected by heterogeneity in the marginal value of time we ended the experiment by measuring the marginal price for the willingness to spend time doing nothing.

We find that students put substantially more time in answering IQ questions when rewards are higher. The effect of extra time investments on test scores is less obvious, and depends on the type and difficulty of the IQ question. When time constraints are very binding the effects disappear, suggesting that people cannot increase mental effort as a substitute for investing more time. We find several personality traits for which the effect of rewards on the time spent to answer a question is significantly smaller than average: performance-motivation, internal locus of control and curiosity. Also components from the five-factor model of personality structure, such as emotional stability and conscientiousness are associated with a low effect of rewards on extra time investments. Students with a high preference for leisure (measured by psychological tests) and a negative fear of failure increase their efforts to answer questions more than average when rewards go up. This also holds for the component measuring openness to new experiences from the five-factor model 
of personality structure.

For the economic preference parameters we find the opposite result. Students with high discount rates, high risk aversion and a high preference for leisure (measured by questions in which the respondent has to tradeoff time and money) tend to decrease time spent on an IQ question more than others, when rewards are increased. Again, the incentives do not always increase performance. Since in general low discount rates and low levels of risk aversion are also associated with favorable behavioral or labor-market outcomes this is surprising. A potential explanation is that economic preference parameters are measured by questions about economic trade-offs. Possibly, people differ in their ability to deal with such trade-offs, explaining why the psychological measures might pick up other aspects of noncognitive skills than the economics preference parameters.

The paper proceeds as follows. Section II describes the set up of the experiment and presents basic information about the several tests included. Section III discusses the measures of noncognitive skills. Section IV presents the results and Section V concludes.

\section{Experiment}

Design

We conducted an experiment with different time constraints and financial incentives on IQ questions to examine the influence of different preferences and types on the performance in this cognitive test. 128 subjects participated in the experiment. They are all Dutch students from Maastricht University and the experiment was conducted in Dutch. The Appendix at the end of the paper provides more background information. The experiment was conducted in four stages.

\section{Personality}

In the first stage of the experiment, subjects were giving answers to statements to determine psychological traits and were asked to make trade-offs to determine relevant economic preference parameters. We selected ten psychological traits that appear to be potentially relevant for the decision to put effort in a test regardless of the reward. In psychology there is a long tradition to search for traits explaining differences in the tendency to perform well. Following the work of Atkinson and Reitman (1958) and Edwards (1959), Hermans (1975) developed Dutch tests for this purpose that are still considered as the norm in the field. We applied shortened versions of Hermans' test of performance-motivation, 
preference for leisure, positive fear of failure and negative fear of failure. We added tests for internal locus of control and social desirability (Rotter scale), enjoyment of success (Steers and Black, 1994), and resilience (Siebert, 1993) because the attitude to relate success and failure to one's own performance and to stay motivated after failure are generally regarded as important elements for success. We also added a test for curiosity (Steers and Black, 1994), because curious people might have more fun solving questions in cognitive tests. The attitude towards work from the World Value Study has been added, since this test is available for a wide variety of countries. In all tests respondents had to answer on a fivepoint scale to what extent statements hold for them. We checked for the reliability of the statements included using Cronbach's alpha. Average normalized scores (reversing scores on negative statements) are used as measures in our analyses. ${ }^{1}$

We also included items from the five-factor model of personality structure ("big five") measuring emotional stability, introversion, openness, agreeableness and conscientiousness. Here respondents have to characterize themselves on a five-point scale between two extreme characterizations. The five-factor model of personality structure described by Goldberg (1990) is introduced as an attempt to summarize the wide spectrum of psychological traits that matter for behavior. This model was developed as a broad model defining five independent categories underlying a number of related personality facets of more specific attributes. It originated already in the 1930s when people tried to organize traits commonly used to develop a taxonomy of measurable characteristics (e.g., Allport and Odbert, 1936).

\section{Preference parameters}

Additionally we included questions to measure economic preference parameters. By posing questions in which respondents are asked to make a trade-off between current and future rewards, certain and risky rewards, and money and leisure, we measured time preference, risk aversion and preference for leisure. In the analyses we apply average scores for each parameter. Risk preference is measured by two series of questions. There are two questions describing a situation in which risk taking behavior is assessed and two sets of questions on deals people can strike with probabilities of getting nothing. By increasing the amount of money at stake we can determine how risk averse subjects are. Figure Ia plots risk preference. The horizontal axis is increasing in risk taking. The average risk preference

\footnotetext{
${ }^{1}$ Scores based on weights obtained from factor analyses provide similar results.
} 
parameter equals 1.239 and the standard deviation is 0.526 .

The discount rate is measured in a similar way but now with questions referring to possible future benefits or future money that can be consumed at some cost in the present. By assessing the willingness of subjects to postpone present consumption for future consumption, we determine the discount rate. Figure Ib plots the discount rate. The horizontal axis is increasing in the discount rate, which should be interpreted as an increasing tendency to value the present more than the future. The average discount rate is 0.247 with a standard deviation of $0.120 .^{2}$

Preference for leisure can be measured both by statements as in the psychological tradition and by imposing explicit trade-offs. We measured the preference for leisure in this economic fashion by two questions giving subjects the opportunity to either trade leisure for money or exchange money for leisure time. Figure Ic plots the preference for leisure, with the horizontal axis increasing in preference for leisure. The average preference for leisure is 0.912 , with a standard deviation of 0.215 .

\section{Cognitive tests}

The second stage of the experiment was a cognitive test consisting of ten IQ questions selected randomly from a set of 80 possible questions. The ten IQ questions are of the following types. Two Raven matrices, two sequences or matrices of numbers, two filling in linking words, one anagram, one sequence or matrix of characters, one "stranger in our midst", and one question from the Cognitive Reflection Test by Frederick (see Frederick, 2005). The first row in Table I reports the mean levels and standards errors of the total score (Panel A) and duration (Panel B) in the second stage, and the same numbers disaggregated by type of IQ question. The score is measured as the fraction of correct answers and duration is measured in seconds used to answer a question.

The third stage was a cognitive test consisting of seven sets of ten questions in which in each set there was a possible time constraint (no time constraint, 60 seconds or 30 seconds) and incentive pay (no pay, $€ 0.10, € 0.40$ or $€ 1.00$ for each correct answer). Subjects always had to complete one set of questions without incentive pay and two sets of questions under each incentive pay regime. So, the maximum earnings in the third stage are $€ 30.00$. The average earnings were $€ 16.53$ (with a standard deviation of $€ 3.44$ ). All respondents had

\footnotetext{
2 The discount rates reported in the literature vary substantially, which seems to be due to the wording of the questions. Evidence shows that the relative position of individuals on the scale is rather stable across questions (e.g., Frederick, Loewenstein and O'Donoghue, 2002). The discount rate reported here is relatively low.
} 
to answer the full set of 80 IQ questions, but we randomized the order to separate the effect of tiredness and experience with the questions from the difficulty of the question. The composition of each set of ten questions was always the same as in the first set described above. After each block of ten questions, there was a one minute break during which subjects could recover but were not allowed to do anything else then sit still. We report in Table I, from row (2) onwards, the scores (Panel A) and duration (Panel B) under different time constraints and incentive pay combinations. The overall picture shows that - in comparison with later questions without time constraints - subjects thought longest when they were first confronted with the IQ questions (81.601 seconds) and scored relatively well (0.622) during the second stage of the experiment. The first column of Table I shows that in general higher incentive pay increases time investments in answering the questions. The scores are higher for any incentive pay although not for the questions with a time constraint of 30 seconds. In this latter case the time constraint seems to be binding because 24.8 percent of the questions are not answered within the 30-second time frame. For the 60-second time limit this is true for only 10.4 percent.

The remaining columns show the mean score and duration by type of IQ question. The scores in Panel A reveal that the Raven matrices, the sequences or matrices of numbers and the Frederick questions have been answered relatively well and that filling in missing words has been most difficult. Furthermore, time limits reduce scores on almost all questions. The most striking effects of time constraints are found for fillings in missing words, the sequence or matrix of characters, and the Frederick questions. Compared to the no limit case, scores are reduced by some 50 percent with a 30-second time limit. In general, scores weakly rise with incentive pay, but not in case of the 30 -second time limit. The most prominent increases are found for the Raven matrices, the sequences or matrices of numbers and the Frederick questions (except for the 30-second time limit).

Panel B shows that subjects spend more time on difficult questions because we observe a negative relationship between duration and scores; with the exception of the "stranger in our midst" questions. Time spent on answering questions increases with incentive pay, except for questions with a 30 -second time limit. The time spent on answering a question reduces dramatically when comparing the no limit to the 60-second limit questions. Comparison of the distributions reveals that most questions that would have taken more time than the limit allows for are answered in the last ten seconds before the time limit (or too late). 
Overall, Table I shows that time constraints exert more impact on test scores than incentive pay does. Putting in time constraints reduces scores, whereas incentive pay increases scores in the no limit case only. Moreover, subjects significantly increase time investments in the case of incentive pay. A further analysis shows that thinking longer affects scores of relatively easy questions (on which people do well), and also the scores of some of the Frederick questions, the sequence or matrix of numbers, the Raven matrices and the "stranger in our midst" questions (see Borghans, Meijers and ter Weel, 2006 for more elaborate results).

\section{Value of Time}

To ensure that students traded-off the benefits of giving a right answer with the costs of investing more time, they were instructed at the beginning of the experiment that every student could leave the experiment room and get paid when ready. However, we also told them that there was the opportunity to stay and take part in the fourth stage. On beforehand this was told to subjects, without them knowing what this stage would be other than that they could earn some additional money. At the beginning of the fourth stage subjects were shown Figure IIa. The horizontal axis measures time in minutes and the vertical axis cumulative earnings. Subjects could participate by sitting still and doing nothing else than watching for a minute to go by. After the first minute they earned $€ 0.75$. After each minute they could choose to either stay or leave. The program reported after each minute of waiting time, and before the decision to stay for another minute, the total amount of money earned so far (this includes the earnings from the previous stage). The maximum number of minutes subjects could wait was 30 , with the thirtieth minute paying $€ 0.01$. The total amount of money at stake during this half hour was $€ 7.10$.

Figure IIb shows the distribution of subjects by the minute after which they completed the experiment. Figure IIb shows that a considerable fraction of subjects $(5.5$ percent) left the experiment immediately. At the other extreme 13.2 percent of the population waited until the $29^{\text {th }}$ minute or stayed until the end. The average waiting time equals 15.92 minutes, with a standard deviation of 8.18 minutes. This equals average earnings of $€ 5.47$ (standard deviation is $€ 1.77$ ). Figure IIc plots the marginal earnings for the last minute a subject stayed. The average marginal earnings equal $€ 0.20$ per minute, with a standard deviation of $€ 0.18$, which equals an hourly rate of $€ 12.00$, which is well above the legal minimum hourly wage. The legal gross minimum hourly wage is set at $€ 6.24$ for a 22 - 
year old person in the Netherlands in 2006. Surveys among students in the Netherlands reveal that students earn about $€ 8$ - $€ 10$ per hour when working next to their studies.

The purpose of this exercise is to measure the value of time and the value of money of each subject. We use this information to deal with differences between subjects regarding how much they care about money. In addition, if some subjects would be in a hurry and only interested in completing the experiment as soon as possible, the average duration of completing a question could be affected. ${ }^{3}$

\section{Noncognitive skills}

\section{Personality}

Table II presents unconditional correlations between the ten personality traits and the five-factor model of personality structure. ${ }^{4}$ In general the correlation coefficients are low, which confirms the measurement of distinct traits. There are some stronger correlations between the ten traits and the big-five items reflecting the clusters to which these traits apparently belong. Interesting correlations are obtained between performance-motivation and the preference for leisure. The strong negative and significant coefficient is consistent with motivated subjects being less eager to enjoy leisure time. The negative correlation between negative fear of failure and emotional stability is consistent with emotionally stable persons being less vulnerable to fears, which is also reflected by the positive correlation between emotional stability and resilience. Introvert subjects do not enjoy success as much as extravert subjects and conscientious subjects have an internal locus of control and score higher on performance-motivation.

\section{Preference Parameters}

Table III presents the correlations between personality traits and the economic preference parameters. In general the correlation coefficients are significant but low. Most correlations are not surprising, such as the negative correlation between internal locus of control and the discount rate, the positive correlation between risk preference and resilience, and the negative correlation between the preference for leisure and negative fear of failure.

\footnotetext{
${ }^{3}$ The experiments were run at different periods during the day. There are no significant differences in the behavior of subjects across different sessions.

${ }^{4}$ Residual correlations with controls for age, family background, gender and region of birth show similar results.
} 


\section{Results}

Which types perform better?

The first question when analyzing the link between noncognitive and cognitive skills is whether personality types are correlated with cognitive skills. ${ }^{5}$ Panel A of Table IV first shows the estimates of a probit model in which we one by one regress personality types on the probability of giving the correct answer. Three different models have been estimated: One without any additional controls, one with controls for the type of cognitive test question and one with controls for the type of cognitive question, the amount of incentive pay and the time constraint. Comparison of the three columns shows that there are no large differences between the three different equations. Subjects who report to have higher levels of performance-motivation, which have a higher positive fear of failure and an internal locus of control, and subjects who are more curious have a higher probability of giving a correct answer. In addition, subjects suffering from negative fear of failure have a lower probability to give the correct answer. Positive fear of failure is associated with tense feelings that improve performance, whereas negative fear of failure is associated with feelings that are harmful for performance.

The measures from the five-factor model of personality structure show that introversion as opposed to extraversion is related to the probability of giving the correct answer. Openness and agreeableness reduce this probability. Generally, the coefficients of the personality test and the five-factor model of personality structure are consistent with selfdisciplined and motivated subjects achieving higher probabilities of giving the correct answer.

The estimates for the economic preference parameters show that subjects with lower discount rates have a higher probability of giving the correct answer, as well as subjects who are more risk averse. The first estimate is consistent with the economic literature suggesting that more intelligent people have lower discount rates. The coefficient for risk preference is surprising since the economic literature suggests that more intelligent people are more able to foresee future events and as a result less risk averse.

Panel B presents estimates for the same models with duration as the dependent variable. Duration is measured as the log of the number of seconds a subject spends on answering a question. The estimates show that subjects with higher levels of motivation and those who are more eager to do well on the test invest more time in answering a question.

\footnotetext{
${ }^{5}$ This analysis includes the answers to questions in the third stage only.
} 
This can be seen from the positive coefficients on performance-motivation, positive fear of failure, resilience and enjoyment of success; and the negative coefficient for the preference for leisure under personality. Another interesting observation is that the other coefficients are associated with fear of failure implying that people who are afraid to give the wrong answer spend more time answering the question (e.g., negative fear of failure, enjoyment of success, and agreeableness).

The results from the economic preference parameters show that less risk-averse subjects and subjects with higher discount rates spend more time answering the questions, which could be explained as these persons having lower levels of self-confidence.

\section{Who is sensitive to incentives?}

The mere correlation between personality traits, preference parameters and cognitive test scores can be the result of causal mechanisms that go in opposite directions. People who are more motivated or more willing to invest might put more effort in their learning and consequently do better on an IQ test, or people with higher cognitive abilities might better understand the importance of certain noncognitive traits and therefore invest more in the development of these traits. A full understanding of these correlations also requires taking parents and teachers into account. In this paper we focus on the question whether noncognitive skills influence the way students perform on a cognitive test, conditional on their true cognitive abilities at the time of the test.

Panel A of Table V reports the estimates of the following model

$$
\operatorname{Pr}\left(C_{q}\right)=A+\beta_{1} P_{q}+\beta_{2} I_{q}+\beta_{3}\left(P^{*} I\right)_{q}+\varepsilon_{q}
$$

where $\operatorname{Pr}\left(C_{q}\right)$ represents the probability of a correct answer to question $q, P_{q}$ is a personality trait or preference parameter, $I_{q}$ is the amount of incentive pay ( $€ 0, € 0.10, € 0.40$ or $€ 1.00$ ), $\left(P^{*} I\right)_{q}$ is an interaction between incentive pay and a personality trait or preference parameter, and $\varepsilon_{q}$ is an error term with the usual assumptions. The coefficient for the $\left(P^{*} I\right)_{q}$ term is of interest because it reveals the responsiveness of different types to incentive pay. There are two potential ways in which a student can adjust his efforts when answering questions in an IQ test. First, subjects might think harder about a question and as a result obtain a higher probability of giving the correct answer. Second, subjects might invest more time on each question. To disentangle these effects we varied the time restrictions for the questions in the test. We estimate two version of this model. First, we 
estimate the model in which we only consider the case in which there is no time constraint for answering a question. Second, we estimate the model with dummies for the different time constraints (no constraints, 60 seconds or 30 seconds). Both models include fixed effects for the type of cognitive test question.

We only report the coefficients on $P_{q}$ and $\left(P^{*} I\right)_{q}$. The coefficients for $P_{q}$ are generally similar to the ones presented in Table IV above. The coefficients for $(P * I)_{q}$ are the most interesting. A positive (negative) coefficient implies that subjects obtain higher (lower) scores when they receive incentive pay. Almost all coefficients are insignificant, revealing no substantial differences between personalities in improving scores when incentives are introduced. This can be the result of either a low preference for money or the inability to respond to incentives by improving scores. Including our measure for the preference for money or the value of time shown and discussed in Figure II does not change the results suggesting that the results are not shaped by differences in the preference for money. The estimates are also consistent with the figures presented in Table I where we showed that subjects do not seem to be able to improve scores when we introduce incentive pay.

Panel B of Table V reports the estimates of the same models for duration:

$$
D_{q}=A+\beta_{1} P_{q}+\beta_{2} I_{q}+\beta_{3}\left(P^{*} I\right)_{q}+\varepsilon_{q}
$$

where $D_{q}$ is the $\log$ of the time taken to answer each question. From this analysis it becomes clear that subjects do respond to incentives in the sense that they invest more time in answering the questions. This is consistent with the numbers in Table I. The $\left(P^{*} I\right)_{q}$ coefficients for successful traits are negative, which implies that subjects with higher scores for these traits invest less time in answering a question when there is incentive pay compared to subjects who score lower on this trait. The coefficients for performance-motivation suggest that subjects who are intrinsically motivated tend to think longer when answering a question, but less so if they are paid relative to subjects who are less motivated. The same goes for curious persons and those who have a relative internal locus of control. When looking at the coefficients for the five-factor model of personality structure, the same result is obtained for relatively emotionally stable and conscientious persons. Finally, the economic preference parameters point into the opposite direction. In particular subjects with lower discount rates are more sensitive to incentive pay and invest less in general. On the other hand, risk-averse persons spend less time when there is no incentive pay and respond 
stronger to incentive pay.

The general message from these estimates is that particular types of persons seem to be more or less sensitive to incentive pay, although the effects on scores are limited.

\section{Implications for economic theory}

The overall picture emerging from the estimates presented in this paper is that our estimates are consistent with different explanations. Motivation and self-discipline seem to be important traits to be successful in real life (e.g. Heckman and Rubinstein, 2001 and Duckworth and Seligman, 2005) and people with these traits generally perform better on the cognitive test (Table IV). However, the response to incentives is twofold.

First, it might be the case that people with successful characteristics respond stronger to incentives because they are economically rational and are only interested in optimizing income. This implies that people with successful traits under-perform on cognitive tests if there is not much at stake. Such a theory is consistent with the findings of Heckman and Rubinstein (2001) who report that high school dropouts obtaining a GED do equally well on cognitive test scores but lack motivation and self-discipline to succeed in most jobs.

Second, it might be the case that people with successful characteristics are always motivated to do their best and do not calculate the net benefits of every action. This shows that persons with favorable noncognitive skills over-perform on cognitive tests.

Our estimates of the responsiveness of economic preference parameters to financial incentives point towards the rational economic model, while our estimates of the personality traits and the five-factor model of personality structure point towards the second view in which highly motivated people try as hard as they can. Perhaps persons with low discount rates respond more to incentives because they are more intelligent and rational. Such an interpretation would be consistent with the findings in Table I and those of Frederick (2005)

who shows that more intelligent people have lower discount rates. On the other hand, estimates for the personality traits show that favorable traits such as performance-motivation, internal locus of control, emotional stability and conscientious go along with lower responses to financial incentives. Reviewing the correlations between the economic parameters and the personality traits and the measures of the five-factor model of personality structure reveals a relatively low correlation coefficient. Our reading of the evidence is that apparently these measures are capturing different dimensions of traits and preferences. This observation is strengthened by the at first sight inconsistent correlation between preference 
for leisure measured as personality trait and preference for leisure measured in the way economists tend to think about preference for leisure (giving up money for leisure time).

\section{Conclusion}

This paper has presented the first direct estimates of the impact of noncognitive skills on cognitive test scores. Our estimates show that subjects respond to financial incentives by investing more time in answering a question. This investment is generally not increasing test scores. In an effort to determine whether different types of persons respond differently to financial incentives we find that favorable economic preference parameters, such as low discount rates and low risk aversion, are associated with strong responses to incentives. On the other hand favorable psychological characteristics, such as performance-motivation and internal locus of control, are associated with lower responses to financial incentives.

Research in this area is relatively new and much can be learned from establishing solid links between the psychological and economic literature. Psychologists have measured behaviors and traits in many ways, whereas economists have focused on preference parameters. Our estimates suggest that both are capturing different dimensions of preferences and traits. Further research is needed to improve understanding concerning the links between these fields to be really able to capture the effects of noncognitive skills and behaviors on cognitive test scores and economic outcomes.

\section{Appendix}

This appendix provides details about the set up of the experiment. Instructions and the program used to conduct the experiment are available upon request.

\section{Participants}

128 subjects participated in the experiment. They were all students from Maastricht University recruited by email through the communication office of the university. The email contained a hyperlink referring to a webpage through which people could register. Upon registration we asked questions about gender, date and place of birth, highest level of education of both parents, and college major.

\section{Sessions and Rooms}

The experiment was run in the week of 15-19 May 2006 in the experimental 
laboratory of the Faculty of Economics and Business Administration at Maastricht University. There were thirteen sessions: Three on Monday, Wednesday, Thursday and Friday and one on Tuesday morning. The sessions lasted for almost 2.5 hours. The morning session started at $8.30 \mathrm{hrs}$, the early afternoon session at $12.00 \mathrm{hrs}$. and the late afternoon session at $15.30 \mathrm{hrs}$. During initial registration we randomly selected subjects into groups of 10-15 subjects and assigned them to sessions. All subjects received an invitation by email. Upon arrival subjects had to wait in front of the laboratory until everybody arrived. There are no differences between outcomes for different groups.

The laboratory consists of two rooms separated by a slide door. In both rooms there are twelve computers available separated by screens, so people cannot see each other. Every subject was assigned to a computer number and login name and password upon arrival. We experimented with rooms consisting of females and males only and with rooms where males sat next to females only and females next to males. There are no significant differences between females sitting next to males and females sitting in a room with females only. The same goes for males. One room was equipped with an air-conditioning system, but this too does not show up in the results. There are also no significant differences between session at different times of the day, supervisor etc.

The supervision during the experiment was always conducted by two persons: One professional and one of the authors. The professional made sure people were not talking and looking at other people's answers (which made no sense because all questions were assigned randomly, so nobody had the same question at the same time). He also guided people to the exit when they completed the experiment. We controlled the progress of the experiment on a master computer. On this computer the progress and cumulative earnings of every participant were followed. After a subject completed the experiment, he had to leave the room to receive his total earnings in cash in a separate room.

\section{Instructions}

Before the sessions started, one of the authors read the instructions to all participants. These instructions are available upon request. Right before the first cognitive test started in stage 2 (without incentives and time constraints), 50 percent of the subjects received a message that it was important to try as hard as one can when completing the cognitive tests. It turns out the instructions have a significant short-run effect but fade away soon (after two sessions). This finding suggests that telling people to put in effort helps to obtain better 
results, but it is only effective in the short term. A possible repetition of the instruction after a couple of sessions might be effective, but we leave this for future research.

\section{Earnings}

All subjects were entitled to receiving a show up fee of $€ 5.00$, which was paid after having finished the entire test. During the cognitive tests they could earn $€ 30.00$ when they answered all questions correctly. In the fourth stage of the experiment $€ 7.10$ could be earned when waiting for another half hour. So, the maximum amount of money that could be earned was €42.10.

The average earnings during the cognitive test were $€ 16.53$. The average earning during the fourth stage of waiting were $€ 5.46$, which is equal to an average waiting time of 15.92 minutes. The overall average earnings during the experiment were $€ 26.99$, which also includes the show up fee.

\section{Software and Data Collection}

The experiment was programmed in PHP/MySQL and subjects completed the experiment using the Microsoft Internet Explorer. All computers showed the login screen upon arrival and when subjects logged on to the experiment they could start. It was not possible to go back and forth in the program so once an answer had been given and the subject had pressed "continue" or once time ran out during questions with a time constraint, the next question appeared on the screen.

The data were collected on a server. The duration of the cognitive test questions is measured in milliseconds. Because server time can be longer when the network is in heavy use, we checked delays. The average delay is about 2 seconds, with no differences between the different sessions.

\section{References}

Allport, G. W., and H. S. Odbert. "Trait-Names: A Psycho-Lexical Study.” Psychological Monographs, 47, 1936.

Atkinson, J.W., and W. Reitman. "Performance as a Function of Motive Strength and Expectancy of Goal Attainment." In J.W. Atkinson (ed.), Motives in Fantasy, Action and Society. Princeton, 1958, 278-287.

Borghans, L., H. Meijers, and B. ter Weel. "Do Financial Incentives Matter for Cognitive Test Scores?" Working Paper, Maastricht University, 2006.

Duckworth, A. L., and M. E. P. Seligman. "Self-Discipline Outdoes IQ in Predicting Academic Performance of Adolescents." Psychological Science, 16(12), 2005, 939-44. 
Edwards, A.L. Edwards Personal Preference Schedule. New York, 1959.

Frederick, S. "Cognitive Reflection and Decision Making." Journal of Economic Perspectives, 19(4), 2005, 24-42.

Frederick, S., G. Loewenstein, and T. O'Donoghue. "Time Discounting and Time Preference: A Critical Review." Journal of Economic Literature, 40(2), 2002, 350-401.

Goldberg, L. R. "An Alternative Description of Personality: The Big Five Factor Structure." Journal of Personality and Social Psychology, 59(6), 1990, 1216-29.

Heckman, J. J., and Y. Rubinstein. "“The Importance of Noncognitive Skills: Lessons from the GED Testing Program." American Economic Review, 91(2), 2001, 145-9.

Hermans, H. Motivatie en Prestatie: Prestatie-Motivatie, Sociale Wenselijkheid, Capaciteiten en Succes. Amsterdam, 1975.

Siebert, Al, The Survivor Personality. Perigee Books/Berkley Publishing Group, 1993.

Steers, Richard M. and J. Stewart Black, Organizational Behavior. New York: HarperCollins College Publishers, 1994. 
Figure I

\section{Preference Parameters}

A: Risk preference

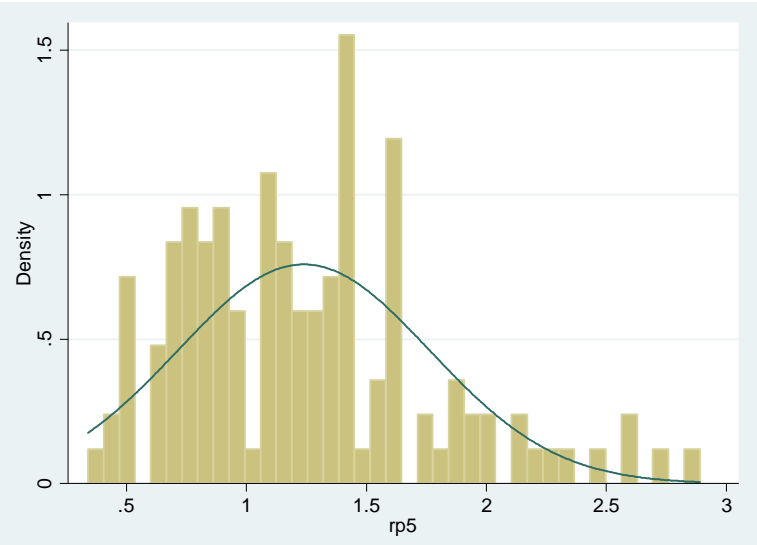

B: Discount rate

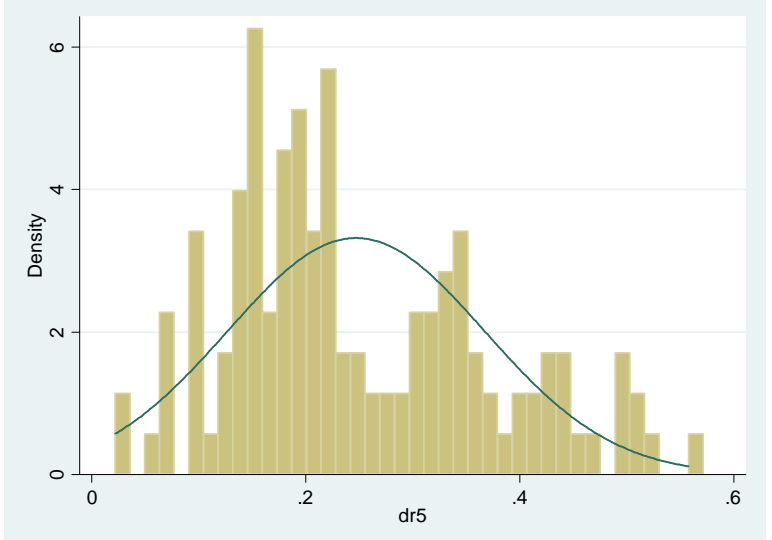

C: Preference for leisure

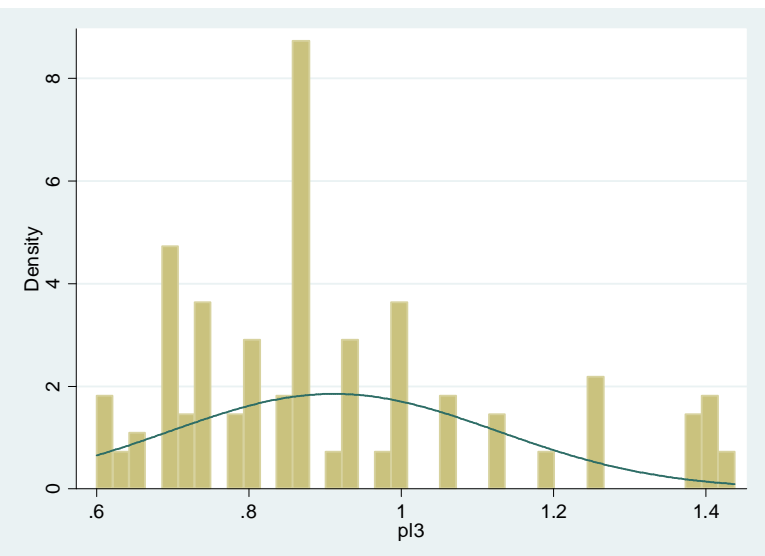

Note: The mean rate of risk preference equals 1.239 , the mean discount rate equals 0.247 and the mean preference for leisure is 0.912 . 
Figure II

\section{Value of Time}

\section{A: Paying Scheme for Waiting}

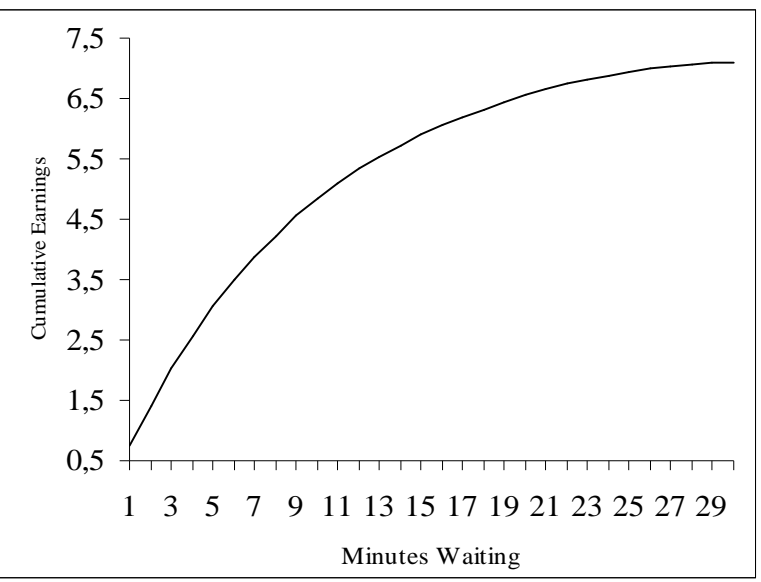

B: Minutes Subjects Have Waited

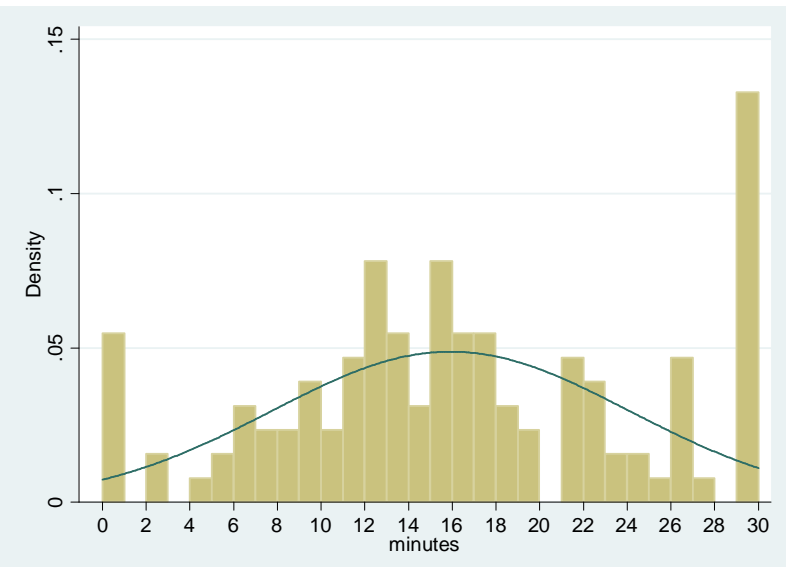

C: Marginal Earnings per Minute

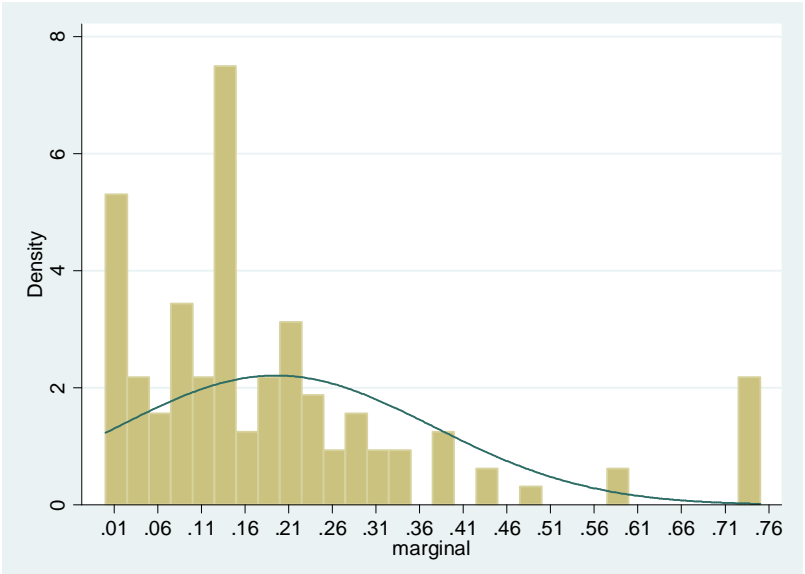


Table I

Cognitive Test Scores

A: Fraction of Correct Answers

\begin{tabular}{|c|c|c|c|c|c|c|c|c|c|}
\hline & & All types & Raven & Numbers & Words & Anagram & Characters & Stranger & Frederick \\
\hline Stage 2 & & $0.622(0.014)$ & $0.891(0.020)$ & $0.688(0.029)$ & $0.391(0.031)$ & $0.563(0.044)$ & $0.492(0.044)$ & $0.523(0.044)$ & $0.703(0.041)$ \\
\hline \multicolumn{10}{|l|}{ Stage 3} \\
\hline \multirow[t]{4}{*}{ No limit } & No pay & $0.598(0.021)$ & $0.880(0.031)$ & $0.556(0.048)$ & $0.426(0.048)$ & $0.648(0.066)$ & $0.481(0.069)$ & $0.444(0.068)$ & $0.685(0.064)$ \\
\hline & $€ 0.10$ & $0.636(0.017)$ & $0.881(0.025)$ & $0.684(0.035)$ & $0.423(0.038)$ & $0.583(0.054)$ & $0.512(0.054)$ & $0.548(0.055)$ & $0.738(0.048)$ \\
\hline & $€ 0.40$ & $0.620(0.018)$ & $0.908(0.025)$ & $0.647(0.040)$ & $0.437(0.042)$ & $0.437(0.059)$ & $0.479(0.060)$ & $0.620(0.058)$ & $0.676(0.056)$ \\
\hline & $€ 1.00$ & $0.646(0.016)$ & $0.924(0.020)$ & $0.694(0.035)$ & $0.459(0.038)$ & $0.553(0.054)$ & $0.541(0.054)$ & $0.424(0.054)$ & $0.788(0.045)$ \\
\hline \multirow[t]{4}{*}{60 seconds } & No pay & $0.503(0.027)$ & $0.786(0.049)$ & $0.514(0.060)$ & $0.371(0.058)$ & $0.457(0.085)$ & $0.229(0.072)$ & $0.486(0.085)$ & $0.514(0.086)$ \\
\hline & $€ 0.10$ & $0.539(0.017)$ & $0.865(0.026)$ & $0.517(0.038)$ & $0.264(0.033)$ & $0.562(0.053)$ & $0.449(0.053)$ & $0.461(0.054)$ & $0.629(0.052)$ \\
\hline & $€ 0.40$ & $0.540(0.016)$ & $0.855(0.026)$ & $0.575(0.036)$ & $0.312(0.034)$ & $0.473(0.052)$ & $0.376(0.050)$ & $0.494(0.052)$ & $0.570(0.052)$ \\
\hline & $€ 1.00$ & $0.575(0.017)$ & $0.859(0.027)$ & $0.565(0.038)$ & $0.365(0.037)$ & $0.529(0.054)$ & $0.329(0.051)$ & $0.612(0.053)$ & $0.706(0.050)$ \\
\hline \multirow[t]{4}{*}{30 seconds } & No pay & $0.431(0.025)$ & $0.679(0.053)$ & $0.397(0.056)$ & $0.231(0.048)$ & $0.564(0.080)$ & $0.231(0.068)$ & $0.692(0.075)$ & $0.205(0.066)$ \\
\hline & $€ 0.10$ & $0.435(0.017)$ & $0.687(0.036)$ & $0.403(0.038)$ & $0.229(0.033)$ & $0.554(0.054)$ & $0.217(0.046)$ & $0.566(0.055)$ & $0.373(0.053)$ \\
\hline & $€ 0.40$ & $0.452(0.016)$ & $0.717(0.033)$ & $0.461(0.037)$ & $0.326(0.035)$ & $0.337(0.050)$ & $0.228(0.044)$ & $0.522(0.052)$ & $0.413(0.052)$ \\
\hline & $€ 1.00$ & $0.427(0.017)$ & $0.709(0.035)$ & $0.459(0.038)$ & $0.198(0.030)$ & $0.430(0.054)$ & $0.221(0.045)$ & $0.570(0.054)$ & $0.314(0.050)$ \\
\hline \multicolumn{10}{|c|}{ B: Duration } \\
\hline & & All types & Raven & Numbers & Words & Anagram & Characters & Stranger & Frederick \\
\hline Stage 2 & & $81.601(2.601)$ & $54.381(2.523)$ & $87.726(6.724)$ & $126.12(8.372)$ & $88.874(6.677)$ & $112.02(7.205)$ & $28.164(2.008)$ & $50.856(3.466)$ \\
\hline \multicolumn{10}{|l|}{ Stage 3} \\
\hline \multirow[t]{4}{*}{ No limit } & No pay & $45.356(1.867)$ & $30.978(1.962)$ & $56.166(5.709)$ & $56.702(4.716)$ & $42.761(4.158)$ & $63.952(6.244)$ & $18.224(2.729)$ & $40.929(3.984)$ \\
\hline & $€ 0.10$ & $57.145(2.040)$ & $39.892(2.551)$ & $68.162(5.657)$ & $75.530(6.013)$ & $59.768(5.074)$ & $72.711(6.390)$ & $23.932(1.679)$ & $47.989(3.953)$ \\
\hline & $€ 0.40$ & $68.242(2.556)$ & $42.104(2.261)$ & $82.536(7.310)$ & $90.492(6.565)$ & $73.525(7.483)$ & $104.58(8.598)$ & $23.379(2.338)$ & $50.668(4.989)$ \\
\hline & $€ 1.00$ & $72.410(2.882)$ & $49.099(4.035)$ & $85.189(9.015)$ & $92.426(7.820)$ & 77.035 (5.892) & $103.13(8.480)$ & $27.377(2.255)$ & $63.124(5.134)$ \\
\hline \multirow[t]{4}{*}{60 seconds } & No pay & $34.978(1.025)$ & $30.644(1.766)$ & $32.693(2.639)$ & $34.319(2.173)$ & $33.579(3.149)$ & $40.148(2.689)$ & $18.585(2.371)$ & $28.691(2.500)$ \\
\hline & $€ 0.10$ & $38.092(0.635)$ & $31.556(1.151)$ & 34.007 (1.694) & $39.543(1.548)$ & $41.659(1.718)$ & $43.308(1.577)$ & $23.882(1.670)$ & $34.724(1.557)$ \\
\hline & $€ 0.40$ & $36.404(0.627)$ & $31.142(1.053)$ & $31.527(1.658)$ & $35.755(1.550)$ & 39.368 (1.678) & $43.235(1.484)$ & $20.787(1.587)$ & $35.773(1.525)$ \\
\hline & $€ 1.00$ & $39.097(0.635)$ & $31.665(1.000)$ & $33.892(1.692)$ & $38.966(1.577)$ & $43.468(1.713)$ & $47.523(1.398)$ & $24.856(1.732)$ & $37.084(1.634)$ \\
\hline \multirow[t]{4}{*}{30 seconds } & No pay & $23.708(0.420)$ & $20.940(0.848)$ & $20.049(1.311)$ & $21.463(0.986)$ & $22.426(1.072)$ & $26.604(0.829)$ & $15.182(1.413)$ & $23.207(1.043)$ \\
\hline & $€ 0.10$ & $23.711(0.292)$ & $21.124(0.529)$ & $20.683(0.871)$ & $21.869(0.846)$ & $22.744(0.781)$ & $24.759(0.814)$ & $15.447(0.850)$ & $23.376(0.760)$ \\
\hline & $€ 0.40$ & $24.155(0.280)$ & $22.103(0.492)$ & $18.882(0.854)$ & $20.792(0.821)$ & $25.097(0.735)$ & $26.797(0.730)$ & $16.560(0.861)$ & $23.584(0.719)$ \\
\hline & $€ 1.00$ & $24.347(0.284)$ & $22.098(0.563)$ & $19.424(0.835)$ & $21.057(0.902)$ & $24.149(0.676)$ & $25.466(0.689)$ & $16.338(0.881)$ & $23.946(0.783)$ \\
\hline
\end{tabular}

Note: Standard errors in brackets. Stage 2 is a stage in which ten IQ questions have to be answered. In Stage 3 seven sets of ten IQ questions have to be answered of which six involve payment. 
Table II

\section{Correlation Coefficients}

Perf-mot Pref lei Pos fear Neg fear Int loc Soc des Curios Resilie Enj suc Att work Emo stab Introver Openness Agreabl Conscien

\section{Personality traits}

\begin{tabular}{|c|c|c|c|c|c|c|c|c|c|}
\hline Perf-mot & 1.0000 & & & & & & & & \\
\hline Pref lei & $\begin{array}{c}-0.4598^{*} \\
0.0000\end{array}$ & 1.0000 & & & & & & & \\
\hline Pos fear & $\begin{array}{l}0.0301 \text { * } \\
0.0023\end{array}$ & $\begin{array}{c}-0.0198 * \\
0.0449\end{array}$ & 1.0000 & & & & & & \\
\hline Neg fear & $\begin{array}{l}0.1766 * \\
0.0000\end{array}$ & $\begin{array}{c}-0.1609 * \\
0.0000\end{array}$ & $\begin{array}{r}-0.0016 \\
0.8736\end{array}$ & 1.0000 & & & & & \\
\hline Int $10 \mathrm{c}$ & $\begin{array}{r}-0.0089 \\
0.3669\end{array}$ & $\begin{array}{c}-0.0523^{*} \\
0.0000\end{array}$ & $\begin{array}{l}0.0479 * \\
0.0000\end{array}$ & $\begin{array}{c}-0.2141 * \\
0.0000\end{array}$ & 1.0000 & & & & \\
\hline Soc des & $\begin{array}{l}0.1680 * \\
0.0000\end{array}$ & $\begin{array}{l}-0.1434 * \\
0.0000\end{array}$ & $\begin{array}{l}0.0773^{*} \\
0.0000\end{array}$ & $\begin{array}{l}0.0299 * \\
0.0024\end{array}$ & $\begin{array}{c}-0.0566^{*} \\
0.0000\end{array}$ & 1.0000 & & & \\
\hline Curios & $\begin{array}{l}0.2802 * \\
0.0000\end{array}$ & $\begin{array}{c}-0.2821^{\star} \\
0.0000\end{array}$ & $\begin{array}{c}-0.0682 \star \\
0.0000\end{array}$ & $\begin{array}{c}-0.1453^{*} \\
0.0000\end{array}$ & $\begin{array}{l}0.1817 * \\
0.0000\end{array}$ & $\begin{array}{c}-0.1181 \star \\
0.0000\end{array}$ & 1.0000 & & \\
\hline Resilie & $\begin{array}{c}-0.0266 * \\
0.0072\end{array}$ & $\begin{array}{c}-0.0331 * \\
0.0008\end{array}$ & $\begin{array}{c}-0.0924 * \\
0.0000\end{array}$ & $\begin{array}{c}-0.2720 * \\
0.0000\end{array}$ & $\begin{array}{l}0.0259 * \\
0.0088\end{array}$ & $\begin{array}{c}-0.0689 * \\
0.0000\end{array}$ & $\begin{array}{l}0.2307 * \\
0.0000\end{array}$ & 1.0000 & \\
\hline Enj suc & $\begin{array}{c}-0.0213 * \\
0.0313\end{array}$ & $\begin{array}{c}-0.1473 * \\
0.0000\end{array}$ & $\begin{array}{c}-0.1663^{*} \\
0.0000\end{array}$ & $\begin{array}{c}-0.1197 * \\
0.0000\end{array}$ & $\begin{array}{l}0.1334 * \\
0.0000\end{array}$ & $\begin{array}{c}-0.2143 * \\
0.0000\end{array}$ & $\begin{array}{l}0.2350 * \\
0.0000\end{array}$ & $\begin{array}{l}0.1539 * \\
0.0000\end{array}$ & \\
\hline Att work & $\begin{array}{l}0.0598 * \\
0.0000\end{array}$ & $\begin{array}{c}-0.2313 * \\
0.0000\end{array}$ & $\begin{array}{c}-0.0629 * \\
0.0000\end{array}$ & $\begin{array}{l}0.0952 * \\
0.0000\end{array}$ & $\begin{array}{l}0.1450 * \\
0.0000\end{array}$ & $\begin{array}{c}-0.0740 * \\
0.0000\end{array}$ & $\begin{array}{l}0.0597 \star \\
0.0000\end{array}$ & $\begin{array}{lc}0.0339 * & -0.1828 * \\
0.0006 & 0.0000\end{array}$ & 1.0000 \\
\hline
\end{tabular}

\section{Five-factor model of personality structure}

\begin{tabular}{|c|c|c|c|c|c|c|c|c|c|c|c|c|c|c|c|}
\hline Emo stab & $-0.0283 *$ & $0.0325 *$ & $-0.0352 *$ & $-0.4513 *$ & $0.1479 *$ & $-0.0397 *$ & $0.1846^{*}$ & $0.5813 *$ & $0.3144 *$ & $-0.0648 *$ & 1.0000 & & & & \\
\hline & 0.0042 & 0.0010 & 0.0004 & 0.0000 & 0.0000 & 0.0001 & 0.0000 & 0.0000 & 0.0000 & 0.0000 & & & & & \\
\hline Introver & $0.0393 *$ & $0.0586 *$ & $0.0628 *$ & $-0.0607 *$ & $-0.0667 \star$ & $0.1656^{*}$ & $-0.1053 *$ & $-0.1852 *$ & $-0.4776^{\star}$ & $-0.0712^{\star}$ & $-0.2205^{\star}$ & 1.0000 & & & \\
\hline & 0.0001 & 0.0000 & 0.0000 & 0.0000 & 0.0000 & 0.0000 & 0.0000 & 0.0000 & 0.0000 & 0.0000 & 0.0000 & & & & \\
\hline Openness & $\begin{array}{c}-0.3958 * \\
0.0000\end{array}$ & $\begin{array}{l}0.3542 * \\
0.0000\end{array}$ & $\begin{array}{l}0.0691 \text { * } \\
0.0000\end{array}$ & $\begin{array}{l}0.0299 * \\
0.0025\end{array}$ & $\begin{array}{c}-0.2502 * \\
0.0000\end{array}$ & $\begin{array}{c}-0.0656^{\star} \\
0.0000\end{array}$ & $\begin{array}{c}-0.1949 * \\
0.0000\end{array}$ & $\begin{array}{l}0.1043^{*} \\
0.0000\end{array}$ & $\begin{array}{c}-0.0986^{*} \\
0.0000\end{array}$ & $\begin{array}{c}-0.0906^{*} \\
0.0000\end{array}$ & $\begin{array}{c}-0.1588 * \\
0.0000\end{array}$ & $\begin{array}{c}-0.0389 * \\
0.0001\end{array}$ & 1.0000 & & \\
\hline Agreeabl & $\begin{array}{l}0.1021 \text { * } \\
0.0000\end{array}$ & $\begin{array}{c}-0.0739 * \\
0.0000\end{array}$ & $\begin{array}{c}-0.0221 * \\
0.0251\end{array}$ & $\begin{array}{l}0.0669 * \\
0.0000\end{array}$ & $\begin{array}{l}0.0379 * \\
0.0001\end{array}$ & $\begin{array}{l}0.1395 * \\
0.0000\end{array}$ & $\begin{array}{l}0.1104 * \\
0.0000\end{array}$ & $\begin{array}{l}0.2483^{*} \\
0.0000\end{array}$ & $\begin{array}{l}0.2506^{*} \\
0.0000\end{array}$ & $\begin{array}{l}0.0396 * \\
0.0001\end{array}$ & $\begin{array}{l}0.2170 * \\
0.0000\end{array}$ & $\begin{array}{c}-0.4729 * \\
0.0000\end{array}$ & $\begin{array}{l}0.1083 * \\
0.0000\end{array}$ & 1.0000 & \\
\hline Conscien & $\begin{array}{l}0.5570 * \\
0.0000\end{array}$ & $\begin{array}{c}-0.3285^{\star} \\
0.0000\end{array}$ & $\begin{array}{c}-0.0933^{*} \\
0.0000\end{array}$ & $\begin{array}{r}-0.0160 \\
0.1064\end{array}$ & $\begin{array}{l}0.2003^{*} \\
0.0000\end{array}$ & $\begin{array}{l}0.1733 * \\
0.0000\end{array}$ & $\begin{array}{l}0.1956 \text { * } \\
0.0000\end{array}$ & $\begin{array}{l}0.0437 \text { * } \\
0.0000\end{array}$ & $\begin{array}{l}0.0969 * \\
0.0000\end{array}$ & $\begin{array}{c}-0.0740 * \\
0.0000\end{array}$ & $\begin{array}{l}0.0968 * \\
0.0000\end{array}$ & $\begin{array}{l}0.0138 \\
0.1615\end{array}$ & $\begin{array}{c}-0.4286^{*} \\
0.0000\end{array}$ & $\begin{array}{l}0.0336 * \\
0.0007\end{array}$ & 1.0000 \\
\hline
\end{tabular}

Note: p-values under correlation coefficient; * is significant at the 5 percent level. 
Table III

\section{Correlation Coefficient between Economic Preference Parameters and Personality Traits}

| Perf-mot Pref lei Pos fear Neg fear Int loc Soc des Curios Resilie Enj suc Att work Emo stab Introver Openness Agreabl Conscien

\begin{tabular}{|c|c|c|c|c|c|c|c|c|c|c|c|c|c|c|c|}
\hline $\begin{array}{l}\text { Discount } \\
\text { rate }\end{array}$ & $\begin{array}{l}0.0300 * \\
0.0045\end{array}$ & $\begin{array}{l}0.0262 * \\
0.0130\end{array}$ & $\begin{array}{r}-0.0093 \\
0.3787\end{array}$ & $\begin{array}{c}-0.0219 * \\
0.0381\end{array}$ & $\begin{array}{c}-0.1178 * \\
0.0000\end{array}$ & $\begin{array}{l}0.0601 \text { * } \\
0.0000\end{array}$ & $\begin{array}{c}-0.0866^{\star} \\
0.0000\end{array}$ & $\begin{array}{c}-0.0504 \text { * } \\
0.0000\end{array}$ & $\begin{array}{l}0.1659 * \\
0.0000\end{array}$ & $\begin{array}{c}-0.1001 * \\
0.0000\end{array}$ & $\begin{array}{l}0.0090 \\
0.3947\end{array}$ & $\begin{array}{c}-0.1293 * \\
0.0000\end{array}$ & $\begin{array}{c}-0.1020 * \\
0.0000\end{array}$ & $\begin{array}{l}0.0699 * \\
0.0000\end{array}$ & $\begin{array}{l}0.0062 \\
0.5553\end{array}$ \\
\hline Risk & $0.0659 *$ & $-0.0853 *$ & $0.0328 *$ & $0.0236 *$ & 0.0099 & $0.0613 *$ & -0.0036 & $0.1226 *$ & $0.0460 *$ & $-0.0262 *$ & $-0.1177 \star$ & $-0.0500 *$ & $0.0804 *$ & $0.1248 *$ & $0.0524 *$ \\
\hline pref & 0.0000 & 0.0000 & 0.0019 & 0.0256 & 0.3494 & 0.0000 & 0.7356 & 0.0000 & 0.0000 & 0.0130 & 0.0000 & 0.0000 & 0.0000 & 0.0000 & 0.0000 \\
\hline Pref for & $0.0313 *$ & $-0.0776 *$ & $0.1007 *$ & $-0.1326 *$ & $0.1460 *$ & $0.1972 *$ & $0.0463 *$ & $0.1023 *$ & $0.0241 *$ & $-0.0380 *$ & 0.0924 * & 0.0414 * & $-0.0248 *$ & $0.0279 *$ & $0.0534 *$ \\
\hline leisure & 0.0031 & 0.0000 & 0.0000 & 0.0000 & 0.0000 & 0.0000 & 0.0000 & 0.0000 & 0.0228 & 0.0003 & 0.0000 & 0.0001 & 0.0189 & 0.0083 & 0.0000 \\
\hline
\end{tabular}

Note: p-values under correlation coefficient; $*$ is significant at the 5 percent level. 
Table IV

Cognitive Test Scores, Personality and Preferences

A: The Effect of Personality and Preferences on the Probability of Giving a Correct Answer

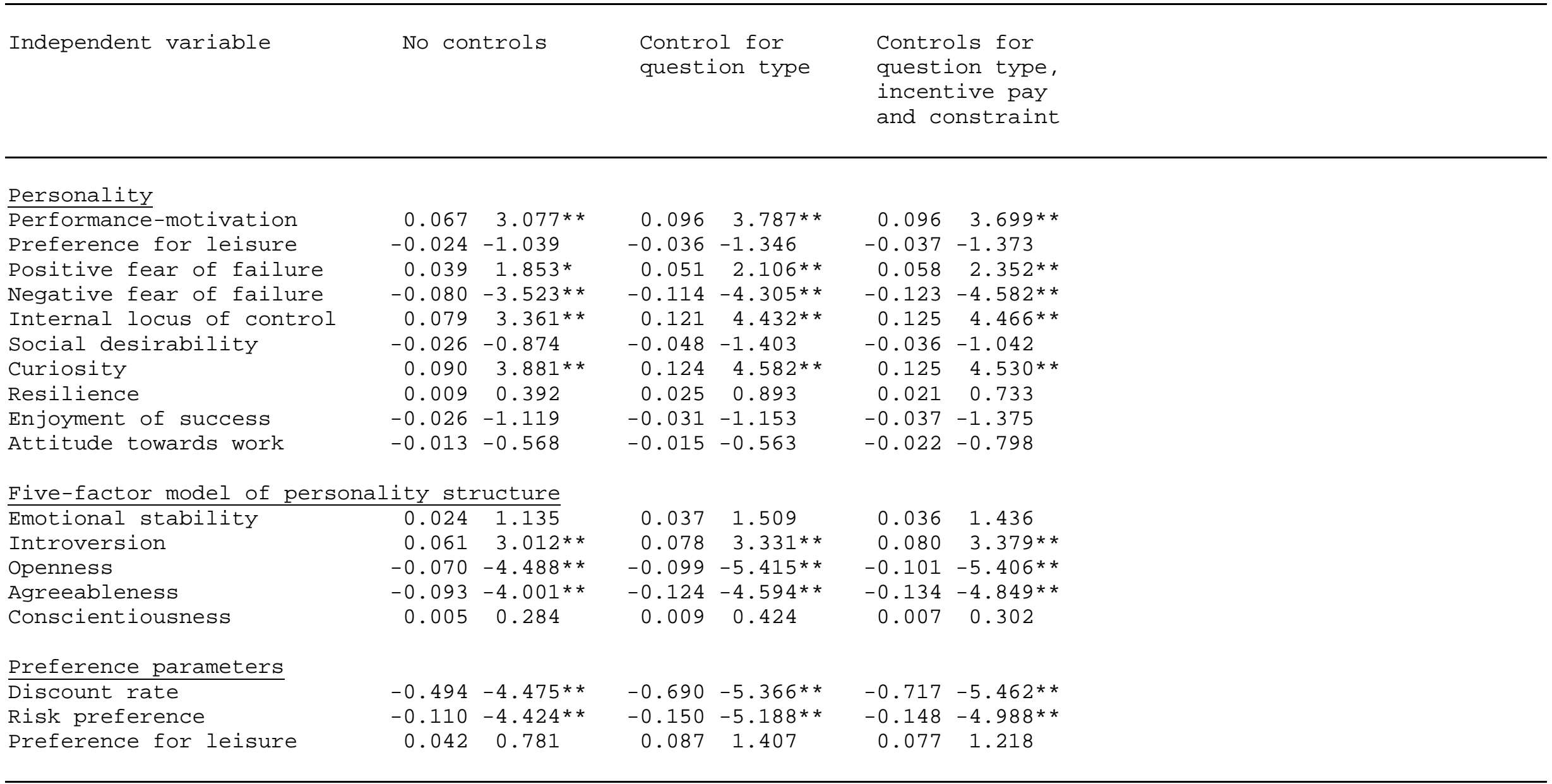


B: The Effect of Personality and Preferences on Duration

\begin{tabular}{|c|c|c|c|}
\hline Independent variable & No controls & $\begin{array}{l}\text { Control for } \\
\text { question type }\end{array}$ & $\begin{array}{l}\text { Controls for } \\
\text { question type, } \\
\text { incentive pay } \\
\text { and constraint }\end{array}$ \\
\hline
\end{tabular}

\begin{tabular}{|c|c|c|c|c|c|c|}
\hline Performance-motivation & 0.030 & $2.216 * *$ & 0.031 & $2.989 * *$ & 0.027 & $2.857 * *$ \\
\hline Preference for leisure & -0.046 & $-3.253 * \star$ & -0.045 & $-4.067 \star \star$ & -0.042 & $-4.213 * \star$ \\
\hline Positive fear of failure & 0.044 & $3.443 * \star$ & 0.045 & $4.471 * \star$ & 0.046 & $5.077 * *$ \\
\hline Negative fear of failure & 0.038 & $2.716 * *$ & 0.036 & $3.329 * *$ & 0.033 & $3.397 * *$ \\
\hline Internal locus of control & 0.009 & 0.611 & 0.009 & 0.761 & 0.009 & 0.850 \\
\hline Social desirability & -0.007 & -0.374 & -0.003 & -0.183 & 0.007 & 0.530 \\
\hline Curiosity & -0.014 & -1.013 & -0.016 & -1.418 & -0.017 & -1.644 \\
\hline Resilience & 0.032 & $2.198 * \star$ & 0.027 & $2.347 \star \star$ & 0.023 & $2.217 * \star$ \\
\hline Enjoyment of success & 0.053 & $3.764 * \star$ & 0.049 & $4.472 * \star$ & 0.046 & $4.651 * *$ \\
\hline Attitude towards work & 0.016 & 1.134 & 0.013 & 1.223 & 0.009 & 0.898 \\
\hline \multicolumn{7}{|c|}{ Five-factor model of personality structure } \\
\hline Emotional stability & 0.009 & 0.701 & 0.008 & 0.762 & 0.003 & 0.375 \\
\hline Introversion & -0.034 & $-2.758 \star \star$ & -0.029 & $-3.042 \star \star$ & -0.031 & $-3.584 *$ \\
\hline Openness & -0.002 & -0.231 & -0.002 & -0.242 & 0.000 & 0.028 \\
\hline Agreeableness & 0.053 & $3.739 * \star$ & 0.047 & $4.287 \star \star$ & 0.044 & $4.395 *$ \\
\hline Conscientiousness & 0.005 & 0.458 & 0.008 & 0.826 & 0.005 & 0.625 \\
\hline \multicolumn{7}{|l|}{ Preference parameters } \\
\hline Discount rate & 0.099 & 1.465 & 0.083 & 1.564 & 0.097 & $2.024 * \star$ \\
\hline Risk preference & 0.041 & $2.711 * \star$ & 0.037 & $3.136 * *$ & 0.050 & $4.610 *$ \\
\hline Preference for leisure & 0.055 & 1.668 & 0.050 & $1.958 *$ & 0.040 & 1.714 \\
\hline
\end{tabular}

Note: T-values in brackets. * implies significant at the 10 percent level; ** implies significant at the 5 percent level or below. All coefficients are the result form individual regressions. 
Table V

The Responsiveness of Personality Traits and Preference Parameters to Incentive Pay

A: Probability of Giving a Correct Answer

No time constraints

$P_{q}$

$\begin{array}{rcrr}0.139 & 2.035 * * & 0.010 & 0.085 \\ 0.001 & 0.016 & -0.097 & -0.812 \\ 0.034 & 0.534 & 0.060 & 0.496 \\ -0.182 & -2.601 * * & 0.008 & 0.065 \\ 0.140 & 1.842 * & 0.004 & 0.033 \\ -0.046 & -0.470 & -0.126 & -0.742 \\ 0.156 & 2.189 * \star & 0.048 & 0.372 \\ -0.019 & -0.274 & 0.151 & 1.239 \\ -0.115 & -1.690 & 0.259 & 1.953 * \\ -0.054 & -0.743 & 0.022 & 0.178\end{array}$

$0.1383 .646 * *$

$-0.071-1.741$

$0.060 \quad 1.635$

$-0.134-3.403 * \star$

$0.1513 .637 * \star$

0.0090 .175

$0.1313 .236 * *$

0.0531 .256

$-0.067-1.650$

$0.004 \quad 0.095$

$-0.054-0.743$

Five-factor model of personality structure

\section{Introversion \\ Openness}

Emotional stability

Agreeableness

Conscientiousness

\section{Preference parameters}

Discount rate

Risk preference

Preference for leisure

$-0.014-0.230$
$0.119-2.013 \star \star$
$-0.087-1.804 \star$
$-0.152-2.206 \star \star$
$-0.037-0.611$
$-1.062-2.909 \star \star$
$-0.134-1.823 \star$
$-0.016-0.093$

$\begin{array}{ll}0.201 & 1.777\end{array}$

$-0.037-0.448$

$-0.033-0.269$

$0.134 \quad 1.377$

$1.3562 .228 * *$

0.0740 .523

$0.265 \quad 0.875$
$-0.113-0.996$

$\begin{array}{rlrr}0.052 & 1.409 & -0.036 & -0.564 \\ 0.063 & 1.759 & 0.042 & 0.668 \\ -0.105 & -3.848 * \star & 0.011 & 0.226 \\ -0.067 & -1.641 & -0.158 & -2.251 * \star \\ -0.017 & -0.503 & 0.055 & 0.940 \\ & & & \\ -0.615 & -3.158 * \star & -0.240 & -0.716 \\ -0.143 & -3.253 * \star & -0.011 & -0.137 \\ 0.051 & 0.542 & 0.063 & 0.383\end{array}$


No time constraints

Independent variable

$P_{q}$

$\begin{array}{rr}0.090 & 2.964 * \star \\ -0.097 & -3.227 * \star \\ 0.048 & 1.720 \\ -0.053 & -1.783 \\ 0.024 & 0.725 \\ 0.050 & 1.114 \\ 0.041 & 1.299 \\ 0.054 & 1.633 \\ 0.073 & 2.395 * \star \\ 0.001 & 0.039\end{array}$

\section{Personality}

Performance-motivation

Preference for leisure

Positive fear of failure

Negative fear of failure

Internal locus of control

Social desirability

Curiosity

Resilience

Enjoyment of success

Attitude towards work
$\left(P^{\star} I\right)_{q}$
Fixed effects for time constraints

$P_{q} \quad\left(P^{\star} I\right)_{q}$

Five-factor model of personality structure

Emotional stability

Introversion

Openness

Agreeableness

Conscientiousness

Preference parameters

Discount rate

Risk preference

Preference for leisure

$$
\begin{array}{cc}
0.011 & 0.399 \\
-0.057 & -2.329 \star \star \\
-0.035 & -1.728 \\
0.044 & 1.443 \\
0.042 & 1.559
\end{array}
$$

0.5383 .551 **

$0.1625 .425 * \star$

$0.2042 .926 * *$

$\begin{array}{rl}-0.130 & -2.624 * \star \\ 0.181 & 3.681 * \star \\ 0.045 & 0.951 \\ 0.183 & 3.576 * \star \\ -0.139 & -2.455 * \star \\ -0.087 & -1.217 \\ -0.120 & -2.228 * \star \\ -0.080 & -1.442 \\ -0.078 & -1.372 \\ -0.049 & -0.940\end{array}$

$-0.106-2.086 * *$ 0.0851 .797

$0.1143 .390 * *$

0.0020 .034

$-0.112-2.676$ **
$0.0614 .336 * *$

$-0.068-4.585 * \star$

$0.0463 .420 * *$

0.0130 .897

$0.025 \quad 1.595$

$0.030 \quad 1.648$

$0.006 \quad 0.395$

0.0211 .278

0.0462 .942 **

$-0.002-0.124$

$-0.000-0.012$

$-0.021-1.568$

$-0.027-2.673 * \star$

$0.0322 .087 * *$

$0.0241 .936 *$

$-0.869-3.311 * \star$

$-0.246-4.244 * \star$

$-0.389-3.061 * *$
$0.0714 .361 * *$

0.0822 .402 *
$0.2012 .918 * \star$
$-0.079-3.158 * *$

$0.0612 .368 * \star$

$0.000 \quad 0.010$

$0.047 \quad 1.770$

$-0.037-1.336$

$-0.055-1.783$

$-0.052-2.080$ **

0.0040 .142

$\begin{array}{lll}0.001 & 0.020\end{array}$

$0.025 \quad 0.959$

$0.008 \quad 0.317$

$-0.024-1.028$

$0.0643 .622 * \star$

$0.027 \quad 1.038$

$-0.043-2.000 * \star$

Note: T-values in brackets. * implies significant at the 10 percent level; ** implies significant at the 5 percent level or below. All coefficients are the result form individual regressions. 


\section{THE UNU-MERIT WORKING PAPER SERIES}

\# 2006-001 A Knowledge Economy Paradigm and its Consequences by Luc Soete.

\# 2006-002 Public-Private Sector Partnerships in an Agricultural System of Innovation: Concepts and Challenges by Andy Hall.

\# 2006-003 Capacity Development for Agricultural Biotechnology in Developing Countries: Concepts, Contexts, Case Studies and Operational Challenges of a Systems Perspective by Andy Hall and Jeroen Dijkman.

\# 2006-004 Technological Capabilities with Different Degree of Coherence: A Comparative Study of Domestic-Oriented vs. Export-Driven Bulgarian Software Companies by Rossitza Rousseva.

\# 2006-005 Small Islands, New Technologies and Globalization: A Case of ICT adoption by SMEs in Mauritius by Kaushalesh Lal and Aveeraj Sharma Peedoly.

\# 2006-006 Beyond Unobserved Heterogeneity in Computer Wage Premiums; and Data on Computer use in Germany, 1997-2001. Double paper by Joan Muysken, Sybrand Schim van der Loeff and Valeria Cheshko.

\# 2006-007 Learning in Local Systems and Global Links: The Otigba Computer Hardware Cluster in Nigeria by Banji Oyelaran-Oyeyinka.

\# 2006-008 Breaking the Fence: Patent Rights and Biomedical Innovation in 'Technology Followers' by Padmashree Gehl Sampath.

\# 2006-009 Taxation and Technology Adoption: A Hotelling Approach by Ben Kriechel and Thomas Ziesemer.

\# 2006-010 Foreign Direct Investment and Technology Spillovers: Evidence from the Indian Manufacturing Sector by Subash Sasidharan.

\# 2006-011 Persistence of Innovation in Dutch Manufacturing: Is it Spurious? By W. Ramond, Pierre Mohnen, Franz Palm and S. Schim van der Loeff.

\# 2006-012 Random Walks and Cointegration Relationships in International Parity Conditions between Germany and USA for the post Bretton-Woods Period by Franco Bevilacqua.

\# 2006-013 On the Persistence of Inequality in the Distribution of Personal Abilities and Income by Adriaan van Zon and $\mathrm{H}$. Kiiver.

\# 2006-014 Foreign Direct Investment, Firm-Level Capabilities and Human Capital Development: Evidence from Kenyan Manufacturing Industry by Geoffrey Gachino.

\# 2006-015 The Determinants of Pharmaceutical R\&D Expenditures: Evidence from Japan by Jörg C. Mahlich and Thomas Roediger-Schluga. 
\# 2006-016 Random Walks and Cointegration Relationships in International Parity Conditions between Germany and USA for the Bretton-Woods Period by Franco Bevilacqua.

\# 2006-017 Concepts and Guidelines for Diagnostic Assessments of Agricultural Innovation Capacity by Andy Hall, Lynn K. Mytelka and Banji Oyelaran-Oyeyinka.

\# 2006-018 Buying and Selling Research and Development Services, 1997-2002 by Julio Rosa, A. Rose and Pierre Mohnen.

\# 2006-019 India's Product Patent Protection Regime: Less or More of 'Pills for the Poor'? by Padmashree Gehl Sampath.

\# 2006-020 Worker Remittances and Growth: The Physical and Human Capital Channels by Thomas Ziesemer.

\# 2006-021 Creating the Capacity to Benefit from Technological Change in Developing Countries by Watu Wamae.

\# 2006-022 A Technology Acquisition Model: The Role of Learning and Innovation by Watu Wamae.

\# 2006-023 Are North-South Technological Spillovers Substantial: A Dynamic Panel Data Model Estimation by Watu Wamae.

\# 2006-024 How “Black” is the Black Sheep Compared to all the others? Turkey and the EU by Semih Ackomak and Saeed Parto.

\# 2006-025 Diffusion Paths for Micro Cogeneration Using Hydrogen in the Netherlands by Mattijs Taanman, Arend de Groot, René Kemp and Bart Verspagen.

\# 2006-027 Innovativity: A Comparison Across Seven European Countries by Pierre Mohnen, Jacques Mairesse and M.J. Dagenais.

\# 2006-028 Empirical Studies of Innovation in the Knowledge Driven Economy by Bronwyn Hall and Jacques Mairesse.

\# 2006-029 Information and Intellectual Property: The Global Challenges by Rishab Aiyer Ghosh and Luc Soete.

\# 2006-030 Absorptive Capacity and Export Diversification in Sub-Saharan African Countries by Alexis Habiyaremye \& Thomas Ziesemer.

\# 2006-031 Indian Pharma Within Global Reach? By Padmashree Gehl Sampath

\# 2006-032 Foreign Ownership, Technological Capabilities and Exports: Evidence from 205 Clothing Firms in Sri Lanka by Ganeshan Wignaraja.

\# 2006-033 (S,s) Pricing: Does the Heterogeneity Wipe Out the Asymmetry on Micro Level? by Zakaria Babutsidze.

\# 2006-034 A Brief History of Mobile Telecommunication in Europe by Theo Dunnewijk and Staffan Hultén. 
\# 2006-035 Irreversible Investment under Uncertainty in Electricity Generation: A Clay-ClayVintage Portfolio Approach with an Application to Climate Change Policy in the $U K$ by Adriaan van Zon and Sabine Fuss.

\# 2006-036 The structure of R\&D collaboration networks in the European Framework Programmes by Thomas Roediger-Schluga and Michael J. Barber.

\# 2006-037 What drives productivity in Tanzanian manufacturing firms: technology or institutions? By M.Goedhuys, N. Janz and P. Mohnen.

\# 2006-038 Economics and Transitions: Lessons from Economic Sub-disciplines by J. van den Bergh \& R. Kemp.

\# 2006-039 Structural Holes, Innovation and the Distribution of Ideas by Robin Cowan and Nicholas Jonard.

\# 2006-040 Social Capital, Innovation and Growth: Evidence from Europe by S. Akcomak and B. ter Weel.

\# 2006-041 Does technology affect network structure? A quantitative analysis of collaborative research projects in two specific EU programmes by $\mathrm{T}$. Roediger-Schluga and $\mathrm{B}$. Dachs.

\# 2006-042 Identifying Age, Cohort and Period Effects in Scientific Research Productivity: Discussion and Illustration Using Simulated and Actual Data on French Physicists by Bronwyn H. Hall, Jacques Mairesse and Laure Turner.

\# 2006-043 Employment, Innovation, and Productivity: Evidence from Italian Microdata by Bronwyn H. Hall, Francesca Lotti and Jacques Mairesse

\# 2006-044 The Role of Noncognitive Skills in Explaining Cognitive Test Scores by Lex Borghans, Huub Meijers \& Bas ter Weel 